\title{
Transfer Prices Assignment with Integrated Production and Marketing Optimization Models
}

\author{
Enrique Parra \\ Universidad de Alcalá (Spain) \\ enrique.parra@uah.es
}

Received: November 2017

Accepted: March 2018

\begin{abstract}
:
Purpose: In decentralized organizations (today a great majority of the large multinational groups), much of the decision-making power is in its individual business units -BUs-. In these cases, the management control system (MCS) uses transfer prices to coordinate actions of the BUs and to evaluate their performance with the goal of guaranteeing the whole corporation optimum. The purpose of the investigation is to design transfer prices that suit this goal.

Design/methodology/approach: Considering the results of the whole company supply chain optimization models (in the presence of seasonality of demand) the question is to design a mechanism that creates optimal incentives for the managers of each business unit to drive the corporation to the optimal performance. Mathematical programming models are used as a start point.

Findings: Different transfer prices computation methods are introduced in this paper for decentralised organizations with two divisions (production and marketing). The methods consider the results of the solution of the whole company supply chain optimization model, if exists, and can be adapted to the type of information available in the company. It is mainly focused on transport costs assignment.

Practical implications: Using the methods proposed in this paper a decentralized corporation can implement more accurate transfer prices to drive the whole organization to the global optimum performance.

Originality/value: The methods proposed are a new contribution to the literature on transfer prices with special emphasis on the practical and easy implementation in a modern corporation with several business units and with high seasonality of demand. Also, the methods proposed are very flexible and can be tuned depending on the type of information available in the company.
\end{abstract}

Keywords: transfer price, optimization models, decentralized organizations

\section{Transfer Prices}

In decentralized organizations (today a great majority of the large multinational groups), much of the decision-making power is in its business units -BUs-. In these cases, the management control system (MCS) uses transfer prices to coordinate actions of the BUs and evaluate their performance with the goal of guaranteeing the whole corporation optimum (Atrill \& McLaney, 2009). A transfer price is the price one BU charges for a product or service supplied to another BU of the same organization. The transfer price creates revenues for the selling BU (for example, production unit) and purchase costs for the buying BU (for example, the marketing division), affecting each BU operating income. These operating incomes can be used to evaluate each BU performance and to motivate their managers. 
The rationale behind transfer prices is that BUs managers, when making decisions, only need to focus on how their decisions will affect their unit's performance without evaluating their impact on the company-wide performance. In this regard, transfer prices ease the BUs managers' decision-making. In a well-designed transfer pricing system, a manager focuses on optimizing the unit performance (refinery or marketing) and in doing so, optimizes the performance of the company as a whole! Nevertheless, to reduce the excessive focus of BUs managers on their own units, many companies compensate BU managers based on both BU and company-wide operating incomes.

It is very undesirable, but managers of business units of large corporations may be tempted to "hunt" results internally through a favorable allocation of transfer prices. Unfortunately, often these efforts are more frequent than reasonable. Therefore, the main question is: how do we calculate transfer prices and who should set the prices?

There are three broad categories of methods for determining transfer prices quoted in literature (Anthony \& Govindarajan, 2006; Bhimani, Horngren, Datar \& Foster, 2008; Horngren, Foster, Data, Rajan \& Ittner, 2008).

Market-based transfer prices: theoretically, we must remember the seminal papers of Hirshleifer (1956) where the marginalist approach was stablished for the transfer pricing problem. "It is well known, that the assumptions on which the marginalist approach relies are unlikely to hold up in practice and it often has difficulties in accommodating the institutional and political factors encountered in specific applications", (Tippet \& Wright, 2006) explains this theoretical approach.

Cost-based transfer prices: can be marginal costs, full costs, plus, eventually, a mark-up. It is widely used (Pfeiffer, Schiller \& Wagner, 2011) but is known that its use has pitfalls (Kren, 2014).

Hybrid transfer prices: the most common form of hybrid prices arises via negotiation between BUs, considering market price and costs.

We will introduce different transfer price methods, focused on transportation costs assignment, which is useful when the company uses (or not) optimization methods to find the global optimum.

\section{Supply Chain Optimization Models}

\subsection{Introduction}

Nowadays, in large corporations it is very common to use mathematical programming models for supply chain optimization. Models use all the supply, production, transport and marketing options and identify the best profit for the whole company. These models can be built using inhouse software, general purpose modelling tools (Fourer, 2015) like AMPL (2017), FICOw XPRESS (2017), LINGO (2017) or industry specialized software. We will use here an example solved with an author's software (Parra, 1999) to illustrate the suggested transfer price.

The optimization is done as follows: once estimated production, demand and storage data are known, a mathematical optimization model establishes - among other results- the transportation quantities from each factory to each warehouse. This enables to calculate the transportation costs for each warehouse and each period, as well as a list of production quantities for each factory, supplies at each warehouse from external suppliers, transportation quantities from factories to warehouses, etc. (Obviously, it is possible to determine the optimal solution with and without external providers to value their opportunity cost).

In addition to this primal information, the model solution provides other valuable information: the dual solution that enables to assess each constraint of the problem and indicate shadow prices.

In large companies with complex distribution systems, it is necessary for commercial organization to establish a sales plan with a high degree of commitment, since these forecasts will force the planning/logistics unit to design a production and distribution plan. If sales forecasts are not met, the company has a cost as the optimum solution for planning of production and transportation cannot be achieved. The same occurs when_production/distribution unit fails on its own commitments.

As a result from the model, transportation costs for each warehouse in each period are computed. We pay attention to transport costs suggesting a fixed transfer price of the product. That is, we will discuss what amount should be 
charged as transportation costs to each warehouse (managed by marketing division). This cost will determine the outcome of each of the divisions/business units of a corporation for each observation period (usually months).

To illustrate the problem, we will use a multiperiod transport model (three periods, one product). The problem, formulated and solved with one author's software, has four factories and ten destinations, which can be considered warehouses from which the capillary distribution is performed (this software and method has been used with dozens of factories/warehouses and many products and periods in Spanish large firms).

\subsection{Model Building Software Driven by Data}

The purpose of this section is to describe the software -TPOS17- used in the example included to discuss the transfer prices methods. This software can be used in large and complex transfer prices computation.

TPOS17 allows the construction of MIP multinode, multiproduct, and multiperiod models of the joint problem of supply, production and transport planning for use in personal computers linked to any optimiser. A non-expert person in modelling techniques, but who knows very well its business, has a tool that finds optimal solutions by simply providing the necessary data and obtaining the solution in an intelligible form. The planner builds a network (in which the nodes can be factories, warehouses, clients and arcs are transport possibilities), and includes the products the company manufacture, the storage capabilities, the manufacturing costs, the transportation costs... only using codes very easy to understand and change. This software has been used by large Spanish companies for both medium term detailed planning and to analyze strategic investments decisions.

TPOS17 allows an easy way to represent, for a non-mathematical user, a wide range of planning models for networks to maximize the production and distribution variable costs margin. The system generates and solves industrial size models (up to 100.000 variables and 10.000 equations); the model building process is based in attribute definition for nodes and arcs in a multiproduct and multiperiod network.

A set of "codes" drives the model building phase. Depending on the content and number of keywords a different model is generated: from didactical to industrial uses. By this way, the user is autonomous: with the same software the user can afford different situations and purposes. TPOS17 allows building different models starting with some intuitive codes written by a non-expert in mathematical programming user but that is an expert in the manufacturing and logistic system.

This software has been mainly designed for multilevel transport and medium complexity production systems. It allows the generation of multiproducts and multiperiods models by the usage of networks.

\subsubsection{TPOS17 Model}

The network is based in $\mathbf{N}$ nodes (suppliers, factories, transshipment sites, destinations, customers) connected, by transport arcs (A), $\mathbf{P}$ products and $\mathbf{T}$ planning horizon periods (periods can be of variable length).

They are the members, respectively, from NODES, PRODUCTS y PERIODS sets. Let $i, i^{\prime} \in N$ (Nodes), $j, j^{\prime} \in P$ (Products), $k \in T$ (Periods).

The generated optimization model purpose is to find the optimal value of the following variables: (for the continuous version, there is an MIP version too)

1. $\operatorname{Pr}(i, j, k)$. Quantity produced of product " $"$ " at node $i$ during period " $k$ ".

2. TR $(i, j, j, k)$. Quantity transformed from product " $j$ " into product " $j$ "” at node " $i$ " during period " $k$ ".

3. $X(i, l, j, k)$. Quantity (if it is generated as a continuous variable) transported from origin node " $i$ " to destination node "l" of product " $i$ " during period "k", or (see below).

4. CS $(i, j, k)$. Quantity consumed (sales = demand satisfaction) of product " $" j$ " at node " $i$ " during period " $k$ ".

5. SS $(i, j, k)$. Quantity of product " $"$ " leaving node " $i$ " during period " $k$ ".

6. EF (i,j,k). Quantity stocked at the end of period "k", of product " $j$ " at node " $i$ ". 
7. $M X(i, j, j, k)$. Quantity of ingredient " $j$ " to be used in the final product " $j$ '” by blending in period " $k$ " at node " $i$ ".

\section{Objective:}

"Maximize the variable margin: Revenues from product sales - Variable Costs (sum of supply, manufacturing, blending, stock and transportation costs)"

First, we will show the mathematical model built by TPOS17 and later we will describe how the user only writes codes and number. He/she does not need to know which variables and constraints are being generated.

Objective function, for the continuous variables case, is (the parameter vectors are explained later):

$$
\begin{aligned}
& \sum_{i} \sum_{j} \sum_{k} \operatorname{Pr}(i, j, k) \cdot C S(i, j, k)-\sum_{i} \sum_{j} \sum_{k} \operatorname{CostProd}(i, j, k) \cdot \operatorname{PX}(i, j, k)- \\
& \operatorname{CostAlm} \cdot \sum_{i} \sum_{j} \sum_{k=1}^{T-1} E F(i, j, k)-\sum_{i} \sum_{i^{\prime} \neq i} \sum_{j} \sum_{k} \operatorname{Cos} \operatorname{Tr}\left(i, i^{\prime}, j\right) \cdot X\left(i, i^{\prime}, j, k\right)- \\
& \sum_{i} \sum_{j} \sum_{j^{\prime}} \sum_{k} \operatorname{Cos} \operatorname{TR}\left(i, j, j^{\prime}, k\right) \cdot \operatorname{TX}\left(i, j, j^{\prime}, k\right)+\sum_{i} \sum_{j} \sum_{j^{\prime}} \sum_{k} M X\left(i, j, j^{\prime}, k\right)
\end{aligned}
$$

Constraints (keywords for model building are mentioned later):

1. Balance for Initial stock, productions, transformations, consumption, shipments and final stock for each node $(i)$, product $(j)$ and period $(k)$.

$$
\begin{aligned}
& E F(i, j, k)-P X(i, j, k)+C S(i, j, k)-\sum_{i^{\prime}} X\left(i^{\prime}, i, j, k\right)+\sum_{i^{\prime}} X\left(i, i^{\prime}, j, k\right)+ \\
& +\sum_{j^{\prime}} \operatorname{TX}\left(i, j^{\prime}, j, k\right)-\sum_{j^{\prime}} \text { Yield }\left(i, j, j^{\prime}, k\right) \cdot \operatorname{TX}\left(i, j^{\prime}, j, k\right) \\
& -\sum_{j^{\prime}} M X\left(i, j^{\prime}, j, k\right)+\sum_{j^{\prime}} M X\left(i, j, j^{\prime}, k\right)=\operatorname{ExIni}(i, j) \\
& \forall(i, j, k=1)
\end{aligned}
$$

2. Quantities $\operatorname{Pr}(i, j, k)$ are produced in node i, from a lower limit, $\operatorname{ProdMin}(i, j, k)$, to an upper limit, $\operatorname{ProdMax}(i, j, k)$, for each product " $j$ " and during each period " $k$ " (keyword PROD) with unitary cost $\operatorname{Cos} \operatorname{Prod}(i, j, k)$. These quantities can be seen like supplies at the node. This is the only way to generate material in the model.

$$
\operatorname{ProdMin}(i, j, k) \leq P X(i, j, k) \leq \operatorname{ProdMax}(i, j, k) \quad \forall(i, j, k)
$$

3. Lower limit (ProdCMin) and upper limit (ProdCMax) exists for joint production (sum for all products) for each period y node. 


$$
\operatorname{ProdCMin}(i, k) \leq \sum_{j} \operatorname{PX}(i, j, k) \leq \operatorname{ProdCMax}(i, k) \quad \forall(i, k)
$$

4. Lower limit (ProdPMin) and upper limit (ProdPMax) exists for a product production in the whole horizon and at each node.

$$
\operatorname{ProdPMin}(i, j) \leq \sum_{k} \operatorname{PX}(i, j, k) \leq \operatorname{ProdPMax}(i, j) \quad \forall(i, j)
$$

5. Any product can be transformed into another with a yield, a unitary cost (CosTR) and lower and upper limits:

$$
\begin{aligned}
\operatorname{TRMin}\left(i, j j, j^{\prime}, k\right) \leq \operatorname{TR}\left(i, j, j^{\prime}, k\right) \leq \operatorname{TRMax}\left(i, j, j^{\prime}, k\right) & \forall\left(i, j, j^{\prime}, k\right) \\
\operatorname{TR} 1 \operatorname{Min}(i, j, k) \leq \sum_{j^{\prime}} \operatorname{TR}\left(i, j, j^{\prime}, k\right) \leq \operatorname{TR} 1 \operatorname{Max}(i, j, k) & \forall(i, j, k) \\
\operatorname{TR} 2 \operatorname{Min}(i, j) \leq \sum_{j^{\prime}} \sum_{k} \operatorname{TR}\left(i, j, j^{\prime}, k\right) \leq \operatorname{TR} 2 \operatorname{Max}(i, j) & \forall(i, j) \\
\operatorname{TR} 3 \operatorname{Min}(i, k) \leq \sum_{j} \sum_{j^{\prime}} \operatorname{TR}\left(i, j, j^{\prime}, k\right) \leq \operatorname{TR} 3 \operatorname{Max}(i, k) & \forall(i, k) \\
\operatorname{TR} 4 \operatorname{Min}(i) \leq \sum_{j} \sum_{j^{\prime}} \sum_{k} \operatorname{TR}\left(i, j, j^{\prime}, k\right) \leq \operatorname{TR} 4 \operatorname{Max}(i) & \forall(i)
\end{aligned}
$$

6. Any product can be stocked from a period to the next one; there exists stock limits (ExMin and ExMax) for each pair product/node, and a total for each node. At the beginning of the planning horizon, the nodes have an initial stock by product (ExIni).

$$
\operatorname{ExMin}(i, j) \leq \operatorname{EF}(i, j, k) \leq \operatorname{ExMax}(i, j) \quad \forall(i, j, k)
$$

7. Sum of all product stocks at node " $i$ " in each of the periods are limited (ExCMin and ExCMax).

$$
\operatorname{ExCMin}(i) \leq \sum_{j} \operatorname{EF}(i, j, k) \leq \operatorname{ExCMax}(i) \quad \forall(i, k)
$$

8. Lower and upper stock limits for each node " $i$ ", product " $j$ ” and period " $k$ ”: ExFMin and ExFMax.

$$
\operatorname{ExFMin}(i, j, k) \leq \operatorname{EF}(i, j, k) \leq \operatorname{ExFMax}(i, j, k) \quad \forall(i, j, k)
$$

9. Lower and upper demand limits (DemMin and DemMax), for each period, product and node; the revenues are the product of the price (Pr) and the demand. This is the way to represent the sales. They are the only usual income from the model.

$$
\operatorname{DemMin}(i, j, k) \leq C S(i, j, k) \leq \operatorname{DemMax}(i, j, k) \quad \forall(i, j, k)
$$

10. Lower and upper transportation limits for each arc (from node " $i$ " to node " $i$ '”), product " $j$ ”" and period " $k$ " (XMin and XMax). This is the way to model the transportation between nodes. 


$$
X \operatorname{Min}(i, j, k) \leq X(i, j, k) \leq X \operatorname{Max}(i, j, k) \quad \forall(i, j, k)
$$

11. Lower and upper limits for the inflow to a node (EntMin and EntMax). To avoid very low sendings it is possible to impose a threshold level defining the outflow variable as a semi continuous variable (MIP version).

$$
\begin{gathered}
\operatorname{EntMin}(i, j, k) \leq \sum_{i^{\prime}} X\left(i^{\prime}, i, j, k\right) \leq \operatorname{EntMax}(i, j, k) \quad \forall(i, j, k) \\
S S(i, j, k)=\sum_{i^{\prime}} X\left(i, i^{\prime}, j, k\right) \quad \forall(i, j, k) \\
\operatorname{SalMin}(i, j, k) \leq S S(i, j, k) \leq \operatorname{SalMax}(i, j, k) \quad \forall(i, j, k)
\end{gathered}
$$

12. Also, it is possible to include special constraints using the variables of the model.

$$
\text { R_Specials Those included in the model }
$$

13. It is possible, as above-mentioned, to force that all the products will be received in a node from the same origin. This is made by adding some constraints (remember $X\left(i, i^{\prime}, j, k\right)$ is binary).

$$
X\left(i, i^{\prime}, 1, k\right)-X\left(i, i^{\prime}, j, k\right) \leq 0 \quad \forall(i, j, k), j \neq 1
$$

14. Blending. It's possible to blend several products at a node to obtain other product with certain limits in properties. It's not allowed to carry out successive blending (pooling problem) to avoid non linearities.

Let $\operatorname{MCMax}(i, j, j$ ', $k)$ and $\operatorname{MCMin}(i, j, j$ ', $k)$ maximum and minimum quantities admitted in product " $j$ "' of the ingredient " $"$ " at node " $i$ " in period " $k$ ".

Let MPMax $\left(i, j^{\prime}, k\right)$ and $\operatorname{MPMin}\left(i, j^{\prime}, k\right)$ maximum and minimum quantities to be obtained of final product " $j$ "' at node " $"$ " in period " $k$ ".

Let CalPro $(i, j, k, l)$ the value of property "l” of product " $j$ "' at node " $i$ " in period " $k$ ".

Let $\operatorname{CalMax}(i, j, k, l)$ and $\operatorname{CalMin}(i, j, k, l)$ maximum and minimum values admitted for property $l$ in final product " $j$ "' at node " $i$ " in period " $k$ ".

When a model includes blending following equations must be added:

$$
\begin{array}{cl}
\operatorname{MCMin}\left(i, j, j^{\prime}, k\right) \leq \operatorname{TX}\left(i, j, j^{\prime}, k\right) \leq \operatorname{MCMax}\left(i, j, j^{\prime}, k\right) & \forall\left(i, j, j^{\prime}, k\right) \\
\operatorname{MPMin}(i, j, k) \leq \sum_{j^{\prime}} \operatorname{TX}\left(i, j^{\prime}, j, k\right) \leq \operatorname{MPMax}(i, j, k) & \forall(i, j, k) \\
\sum_{j^{\prime}}\left(\operatorname{CaIPro}\left(i, j^{\prime}, k, l\right)-\operatorname{CalMax}(i, j, k, l)\right) \operatorname{TX}\left(i, j^{\prime}, j, k\right) \leq 0 & \forall(i, j, k, l) \\
-\sum_{j^{\prime}}\left(\operatorname{CaIPro}\left(i, j^{\prime}, k, l\right)-\operatorname{CalMin}(i, j, k, l)\right) \operatorname{TX}\left(i, j^{\prime}, j, k\right) \leq 0 & \forall(i, j, k, l)
\end{array}
$$

\subsubsection{How Users Generate the Model}

For the end user, the system is a black box; the user feeds it with data, very intuitive, and gets a solution in a very easy format. This is the most important TPOS17 feature. 
Table 1 shows the type of data and the keywords used to build a model. Table 2 shows an example of a model with the codes in Table 1.

1. General: "TITLE" (titles), "COSTALM" (Stock cost).

2. Structure: "NODES" (multinode models), "PRODUCTS" (multiproduct), "PERIODS" (multiperiod), "NET" (transportation arcs).

3. Stocks: "ALMC" (joint limits), "EXINI" (initial stock and limits), "EF" (stock limits).

4. Production: "PROD" (limits and production cost), "PRODC", "PRODP" (limits).

5. Demand: "DEM" (limits and price for the sales).

6. Transport: "INF" (inflow limits), "OUT" (outflow limits, could be semi-continuous), "X" (arc/products/periods limits).

7. Conversions / Transformations: "TR" (feasibility, limits and costs for transformation from one product to another), "TR1", "TR2", "TR3", "TR4" (other limits).

8. Blending: "MX" (possibilities, limits \& costs of blending some products to get other), "MC", "CA", "CP", (blending data).

9. Special constraints : "RE", "COE" . Any other constraint over the variables.

Table 1. Codes for defining models

\begin{tabular}{|c|c|}
\hline Title y other data & $\begin{array}{l}\text { "TITLE","Test Version 3.1" "tons" "euros" } \\
\text { "CostAlm",1 }\end{array}$ \\
\hline \multirow[t]{3}{*}{ Products } & "PRODUCTS",2 \\
\hline & "Type G","G" \\
\hline & "Type E","E" \\
\hline \multirow[t]{3}{*}{ Periods } & "PERIODS",2 \\
\hline & "Jan16","1",31 \\
\hline & "Feb16","2",28 \\
\hline Nodes & "NODES",19 \\
\hline \multirow[t]{2}{*}{ Factories } & "Factory 1","FAC1",0,1,0,1,1,0,2 \\
\hline & "Factory 2","FAC2",0,1,0,1,1,0,2 \\
\hline \multirow[t]{2}{*}{ Warehouses } & "Wareh 1"," WH1",1,0,0,0,1,1,2 \\
\hline & "Wareh 2","WH2",1,0,0,0,1,1,2 \\
\hline \multirow[t]{2}{*}{.Clients } & "Client 01","CLI01",100,0,1,0,0,1,0 \\
\hline & $\begin{array}{l}\text {... definition of the } 15 \text { customers like nodes } \\
\text { "Client 15","CLI15",100,0,1,0,0,1,0 }\end{array}$ \\
\hline Initial Stock & "EXINI","******",1000,0,200004 \\
\hline Stocks limits & "ALMC","*****",0,100003 \\
\hline Production (total) & "PRODC",,******",0,100001 \\
\hline Production (joint) & "PRODP","******",0,200002 \\
\hline Inflows Limits & "INF","*******",0,10000 \\
\hline Outflow Limits & $\begin{array}{l}\text { "OUT","*******",50,100000 } \\
\text { "OUT","WH2G1",20,100000 }\end{array}$ \\
\hline Production limits & $\begin{array}{l}\text { "PROD","*******", } 0,0,0 \\
\text { "PROD","FAC1G*",0,3059,1 } \\
\text {... rest of limits }\end{array}$ \\
\hline Transformation $G$ intc & $\begin{array}{l}\text { in FAC1 } \\
\text { "TR","FAC1GE*",1,11,0,3059 } \\
\text { "TR","FAC2GE*",1,12,0,4210 }\end{array}$ \\
\hline Customer demand & $\begin{array}{l}\text { "DEM","********",0,0,0 } \\
\text { "DEM","CLI01**",93,93,1000 }\end{array}$ \\
\hline & $\begin{array}{c}\text {... rest of demands } \\
\text { "DEM","CLI15**",30,30,1000 }\end{array}$ \\
\hline Network and cost & $\begin{array}{l}\text { "NET","FAC1","WH1",61,31 } \\
\text { "NET","FAC1","WH1",91,67 }\end{array}$ \\
\hline Transportation limits & $\begin{array}{l}\text {... rest of transportation cost } \\
\text { NET",,WH2","CLI15",94,34 } \\
\text { "X" "*****CLI15**" } 11111 \\
\text { "X" "FAC1WH2E1" } 121000\end{array}$ \\
\hline
\end{tabular}

Table 2. A simple model 
The data for any type of model can be read from databases, spreadsheets, etc. Using this data, the model is generated and solved by the software. Optimal solution can be analyzed using other software because the solution is reported in user language or to be included in some database system (Multidimensional databases are recommended).

\subsection{Example for Transfer Price Computations}

In general situations, TPOS17 can be used for complex computations with many factories, warehouses, products and periods combined or not with production optimization.

Examples of real problems solved by the author are: 1) a Spanish oil refinery that manages 3 refineries, up to 8 products, 40 destinations and several weeks planning horizon in short-term planning or a whole year in medium-term planning; 2) a sugar Company with very high seasonal demand and production; this model includes 76 nodes, multilevel distribution for 5 products for a whole year that drives to 5.000 equations and 100.00 variables model. Both must establish transfer prices.

To illustrate the methods proposed for transfer prices computations a simple, but multiperiod transportation model (14 nodes, 4 factories, 10 warehouses), is solved with the software described.

The data is prepared to force different transportation solutions for each period and to generate different transportation costs for each period. This will allow to discuss later how to allocate these costs to the different businesses.

It has been assumed that transport arcs always have the same unit cost and that there is seasonality in the production capacity of factories and in the demand of customer as shown in Tables 3 and 4 .

\begin{tabular}{|r|r|r|r|r|}
\hline \multirow{2}{*}{} & \multicolumn{1}{|c|}{ Initial } & \multicolumn{3}{|c|}{ Production by periods } \\
\cline { 2 - 5 } & Stock & \multicolumn{1}{c|}{ P1 } & \multicolumn{1}{|c|}{ P2 } & \multicolumn{1}{c|}{ P3 } \\
\hline FAC1 & 100 & 200 & 0 & 200 \\
\hline FAC2 & 100 & 300 & 200 & 0 \\
\hline FAC3 & 100 & 200 & 0 & 0 \\
\hline FAC4 & 100 & 200 & 0 & 0 \\
\hline
\end{tabular}

Table 3. Initial stock and production

\begin{tabular}{|c|r|r|r|}
\hline & P1 & P2 & P3 \\
\hline WH1 & 5 & 5 & 0 \\
\hline WH2 & 10 & 5 & 5 \\
\hline WH3 & 20 & 10 & 10 \\
\hline WH5 & 0 & 20 & 49 \\
\hline WH4 & 0 & 0 & 100 \\
\hline WH6 & 50 & 50 & 100 \\
\hline WH7 & 100 & 0 & 200 \\
\hline WH8 & 20 & 20 & 20 \\
\hline WH9 & 20 & 40 & 20 \\
\hline WH10 & 0 & 60 & 60 \\
\hline
\end{tabular}

Table 4. Demand by warehouse 


\begin{tabular}{|c|r|r|r|r|}
\hline \multirow{2}{*}{ Destination } & \multicolumn{5}{|c|}{ Origin } \\
\cline { 2 - 5 } & \multicolumn{1}{|c|}{ FAC1 } & \multicolumn{1}{|c|}{ FAC2 } & \multicolumn{1}{c|}{ FAC3 } & \multicolumn{1}{c|}{ FAC4 } \\
\hline WH1 & 8.00 & 2.43 & 5.36 & 5.83 \\
\hline WH2 & 4.84 & 6.18 & 3.42 & 12.84 \\
\hline WH3 & 4.07 & 2.56 & 3.18 & 8.11 \\
\hline WH4 & 1.66 & 5.34 & 4.38 & 8.68 \\
\hline WH5 & 11.72 & 5.38 & 7.72 & 11.18 \\
\hline WH6 & 8.96 & 2.55 & 4.96 & 7.84 \\
\hline WH7 & 5.63 & 1.15 & 4.01 & 6.21 \\
\hline WH8 & 2.19 & 5.16 & 6.75 & 5.90 \\
\hline WH9 & 9.70 & 4.37 & 7.55 & 4.37 \\
\hline WH10 & 4.60 & 4.67 & 7.16 & 3.49 \\
\hline
\end{tabular}

Table 5. Transportation costs from factories to warehouses

Table 6 summarizes optimal solution for each period (P1, P2, P3)

\begin{tabular}{|c|r|r|r|r|r|r|r|r|r|}
\hline & \multicolumn{3}{|c|}{ Quantities received } & \multicolumn{3}{c|}{ Unit cost } & \multicolumn{3}{c|}{ Dual } \\
\hline Destination & \multicolumn{1}{|c|}{ P1 } & \multicolumn{1}{c|}{ P2 } & \multicolumn{1}{c|}{ P3 } & \multicolumn{1}{c|}{ P1 } & \multicolumn{1}{c|}{ P2 } & P3 & P1 & P2 & P3 \\
\hline WH1 & 5.00 & 5.00 & & 2.43 & 2.43 & & 2.43 & 2.43 \\
\hline WH2 & 10.00 & 5.00 & 5.00 & 3.42 & 6.18 & 4.84 & 3.42 & 6.18 & 6.60 \\
\hline WH3 & 20.00 & 10.00 & 10.00 & 2.56 & 2.56 & 4.07 & 2.56 & 2.56 & 5.83 \\
\hline WH4 & & & 100.00 & & & 1.66 & & & 3.42 \\
\hline WH5 & & 20.00 & 50.00 & & 5.38 & 7.72 & & 5.38 & 11.55 \\
\hline WH6 & 50.00 & 50.00 & 100.00 & 2.55 & 2.55 & 3.76 & 2.55 & 2.55 & 8.79 \\
\hline WH7 & 100.00 & & 200.00 & 1.15 & & 4.52 & 1.15 & & 7.39 \\
\hline WH8 & 20.00 & 20.00 & 20.00 & 2.19 & 2.19 & 2.19 & 2.19 & 3.95 & 3.95 \\
\hline WH9 & 20.00 & 40.00 & 20.00 & 4.37 & 4.37 & 4.37 & 4.37 & 4.37 & 5.55 \\
\hline WH10 & & 60.00 & 60.00 & & 4.38 & 3.49 & & 4.67 & 4.67 \\
\hline
\end{tabular}

Table 6. Solution of a multiperiod model

These findings provide the optimal solution for the production and distribution of the firm; i.e. the sum of production and marketing business units. To obtain that optimal solution a mathematical programming which has considered the availability of the factories is used (some of them could be closed due to maintenance reasons, for example).

Following these results, the transportation costs allocated to each of the warehouses need to be calculated. The goal is to determine what is the transfer pricing for each product at the warehouse level. The price should include the product price and the transportation costs. For this example, we have assumed the same price across the different options, with the goal of focusing on transportation costs. All the assumptions applied to the transportation costs can also be extrapolated to the product value.

In view of these findings, it has calculated the cost of transportation that is to be attributed to each store as distribution costs. It is i.e., determine what the price of transfer of the product in every store. This price includes the price of the product over the cost of transportation. In this example we assume that the price of product is 
always same as to put focus on transport costs. All the considerations that are made in this work to the cost of transportation can be extrapolated to the value of the product.

Transfer pricing (Ptit) between the distribution business unit and the commercial business unit needs to be determined for each warehouse and each period:

$$
\text { PTit }=\text { PC }+ \text { CTi, }
$$

where

PC is the price of the product (constant) and

CTit is the transportation cost to each of the warehouses in each of the periods.

This cost will end in the P\&L (profit \& loss) account of the commercial business unit and will help determine profitability

The global optimization exercise yields the following results:

1. The commercial business unit would like the warehouses to be fulfilled by the Factory with the lower costs:

a. For example, warehouse 1, fulfilled by Factory 2 (unit cost 2.43).

b. warehouse 2 from Factory 3 (unit cost 3.42).

c. Warehouse 3 from Factory 3 (unit cost 2.56) and so on

d. Therefore, the commercial business unit will suggest the above transfer price must be used. Moreover, it might already be using the above transfer pricing numbers when determining any commercial offers.

2. On the other hand, the production business unit wants to get compensated for the actual cost it has incurred.

3. They both agree on $\mathrm{WH} 1$ : real cost of 2.43 for each period.

4. However, that is not the case for warehouse 2:

a. During period 1, cost will be 3.42, from Factory 3, the one that produces at the minimum cost. But, during period 2, unit cost goes up by $81 \%$ (from 3.42 to 6.18) since demand needs to be served from $\mathrm{F} 2$ and not $\mathrm{F} 3$, idle in this period.

b. Something similar occurs during period 3: cost is 4.84 ( $42 \%$ higher than during period 1$)$, since now the efficient fulfilment is from F1.

5. The production business unit wishes to charge $81 \%$ more to period 2 that to period 1 . The commercial BU doesn't understand or support the decision. In fact, it will likely argue that with those transportation costs it is not profitable for them to serve the clients in that area.

If the company is in the process of elaborating the annual budgeting or in the monthly planning phase, facing that information, the commercial business unit might want to adjust the commercial plan in line with the transportation costs.

Moreover, within the creation of the plans and budgets deviations can happen. Having clear information of the commercial plan (and production plan availability) per period allows optimization of the transportation. Not meeting the commercial plan (only marginally) will imply a marginal cost equivalent to the one provided in Table 6 (column dual):

- Marginal cost of demand in WH1 during period 1 is the same as the average cost per month (2.43). Slight variations will not alter transportation costs

- However, small variations in $\mathrm{WH} 2$ demand have a large impact in cost: for example, fulfilment cost to WH5 in period 5 has an average cost of 7.72 (to fulfil 50 units), but the marginal cost is $11.55-50 \%$ more 
Marginal costs are calculated following a new optimization model. If the forecast error is known in advance, it is possible to generate a new optimal plan. As you can see, the marginal cost (11.55), it's not in line with any of the transportation costs available.

Optimization models search for the best possible solution at any point in time with a set of available information. Changes to the plan are collected by an accounting system, registering in every period (generally natural months) the actual transportation costs

If stocking is available, the problem becomes even more complex. At any point in time, sales will not match with transportation costs. The company needs to decide what costs to allocate to the sales in this period, when transportation happened in previous periods.

After looking at the monthly differences caused by seasonality of production and demand, the question that needs to be answered is: what transportation costs should be assigned to each warehouse in each period?

This is an example of the transfer pricing issues that companies with different business units face

In the following section, different alternatives are suggested to compute transfer prices depending on the available information.

\section{Transport Costs in Transfer Prices}

From the above, we draw a first conclusion: it is wrong to account for actual transport costs, as the costs to be included in the calculation of marketing margins. At least a method of accumulation and smoothing should be implemented.

The common accounting methods are usually away from the idea of opportunity cost of transport costs. A method that tries to approach the values of "market" will enable a more precise allocation of costs and, therefore, better measure the margins and the profitability of different divisions.

Consider that average annual cost (AAC) means averaging a full year when the production and distribution situation may have changed. In addition, the AAC method does not capture the seasonality of distribution, which may suggest different solutions and distribution strategies.

For these situations three variants of cost allocation are suggested. Each variant is appropriate according to whether the company can use optimization models (like has been shown above) or not, and if there is a market price.

The three variants are explained:

\section{A. There is a market price (unusual situation).}

With this expression, we mean that it is possible for the marketing division to get the product and its transport to the logistics center, from which it is supplied to its customers at a transport (and product) market price, since there are other manufacturers and could theoretically supply them. That is, there is a market opportunity cost.

In this case, transfer Price between business units must be the market Price:

$$
\text { PTit }=\text { MPit }
$$

Where, $\mathrm{MP}_{\mathrm{it}}$ is the product market price allocated in warehouse $\mathrm{i}$ during period $\mathrm{t}$.

The business planning center of the firm will allocate in the commercial division a transport cost equal to PTit. In certain circumstances it could be lower than the internal cost for the corporation. This calculation leads to a difference between the actual accounting transport cost (TC) and those charges to sales (PTit). The difference TCC - TPit is directly a cost or profit of the manufacturing-distribution unit. In this way, it is possible to separate the marketing function of the producer and study their respective profitability.

Unfortunately this situation is not frequent since, usually, each manufacturer sells and distributes its products without the possibility of going to competitors to save logistics costs. 
B. There is no market price - situation more frequent than the previous one - and the company has a planning system based on mathematical programming models and, so, can calculate dual prices.

In this case, the business planning center of the firm should inform the commercial division of two data: average cost and marginal cost. The first will be applied to the planned quantity and the second to the excess over it.

If the commercial division fulfills the commitment that was included for each moment in the distribution plan, it is charged with the computed cost in the optimal plan (say, standard cost).

So, the deviation from the plan will mean an extra cost that can be measured roughly with optimization model dual price. This will be an approximate calculation because, when implementing the plan, different breaches will happen. To evaluate its exact cost, the optimization model would have to be solved with actual data. This re-optimization effort is not always justified for an exact allocation of costs.

In our example,

- the "WH6" center will be charged a unit cost of 2.55 to the first 50 units sold in Period 1 and Period 2, which were the forecasts communicated to the planner by the marketing division, as required by those centers.

- In Period 3, a unit cost of 3.76 will be charged while each unit excess will be charged at 8.79 .

- Note that in Period 1 and Period 2 the excesses will be attributed to the same unit cost as the average. This introduces the question of marginal costs validity; as is known, it is easy to obtain these ranges in linear programming, since any commercial optimization software reports them.

For simplicity to the business managers, another possibility it is to establish a standard cost based on the budget and then this standard cost is replaced by an updated calculation from actual costs: i.e. with a moving average of the real costs instead of two values.

For example, Table 7 shows the standard transfer price to use for each warehouse:

\begin{tabular}{|c|r|}
\hline Warehouse & Standard transfer price \\
\hline WH1 & 2.4 \\
\hline WH2 & 4.5 \\
\hline WH3 & 2.9 \\
\hline WH4 & 1.7 \\
\hline WH5 & 7.1 \\
\hline WH6 & 3.2 \\
\hline WH7 & 3.4 \\
\hline WH8 & 2.2 \\
\hline WH9 & 4.4 \\
\hline WH10 & 3.9 \\
\hline
\end{tabular}

Table 7. Solution of a multiperiod model 
C. There is no market price and the company does not have planning models with mathematical programming or is not possible to calculate the dual prices (this is undoubtedly the most widespread of situations).

In this case as there is no optimization model, it must be used the budget data for one year and perform a calculation with moving average of several periods that give stability to the costs attributable to marketing.

This is a way to quickly charge costs to the marketing division according with the evolution of logistics costs without the over-attenuating effects of the annual average.

This method improves LIFO cost allocation since it will pick up too quickly a good or bad logistical situation that would create bewilderment in the system of commercial margins inducing to make hasty decisions on price policy or other marketing actions.

This is a good approximation to the opportunity cost but not so sharp than using last known cost.

Compared to the FIFO method, the advantages are evident, since FIFO masks the recent events for a long time and can misrepresent the calculated commercial margins.

In practice, in consolidated logistics systems with a seasonal behavior in production and sales, it can be considered reasonable to impute transportation costs with a three-month moving average, as advised by the cited seasonality.

The procedure is summarized as follows:

A. Accounting monthly actual transport costs by the supply of each of the distribution centers

B. Calculation of the average unit cost of the last three last months

C. Allocation of the calculated unit cost to the sales made in the current month

D. Updating the balance of undistributed costs (i.e. those which are part of the product stock in distribution centers) and those in the production P\&L account.

In our example,

- WH6, in Period 1, will have an imputation of transportation cost, calculated from the average cost of Period-2, Period -1 and Period 1.

- In Period 3 the quarterly moving average gives us an imputable unit cost of 3.15 .

- The recent increase in costs is recognized (in Period 3 it was 3.76), but the method enables to wait for data of the following months to transfer the strong rise from the 2.55 of Period 1 and Period 2 to 3.76 of Period 3.

- Finally, remember that if there is an optimization model, it is possible to know that the excess sales over the 100 units expected for Period 3 will cost you 8.79!

\section{Conclusions}

In an organization with two divisions or business units (manufacturing-distribution, on the one hand, and marketing, on the other hand), there is the practical problem of allocation of distribution costs (and in general product costs) to establish a transfer price between this business units to correctly evaluate the profitability of each one of them and to improve the incentives of each division for acting optimally.

A method of allocation is proposed for those companies that have dual information from mathematical programming models that optimize production and distribution jointly, and another one for those that do not have implemented the use of such models.

These computations must be done by corporate management control to assure business global optimization.

\section{Acknowledgments}

I would like to thank Isabel Gil for the revision of the English manuscript. 


\section{Declaration of Conflicting Interests}

The authors declared no potential conflicts of interest with respect to the research, authorship, and/or publication of this article.

\section{Funding}

The authors received no financial support for the research, authorship, and/or publication of this article.

\section{References}

AMPL (2017). AMPL modeling language and system. http://ampl.com/products/

Anthony, R., \& Govindarajan, V. (2006). Management Control Systems (12th Ed.). McGraw-Hill Education.

Atrill, P., \& McLaney, E. (2009). Management Accounting for Decision Makers. London: Pearson.

Bhimani, A., Horngren, C., Datar, S., \& Foster, G. (2008). Management and Cost Accounting (4th Ed.). FT Prentice Hall.

FICOw XPRESSS (2017). XPRESS Opt Suite. http://www.fico.com/en/products/fico-xpress-optimization-suite

Fourer, R. (2015). Linear Programming: Software Survey. ORMS Today. Informs, 42(3).

Hirshleifer, J. (1956). On the economics of transfer pricing. Journal of Business, 29, 172-184. https://doi.org/10.1086/294110

Horngren, C.T., Foster, G.T., Datar, S.M., Rajan, M.V., \& Ittner, C. (2008). Cost accounting: a managerial emphasis (13th Ed.). Upper Saddle River: Pearson/Prentice Hall.

Kren, L. (2014). Common Pitfalls of Cost-Plus Transfer Pricing. CPA Journal, June.

LINGO (2017). Optimization Modeling Software for Linear, Nonlinear, and Integer Programming. Retrieved from: https://www.lindo.com/index.php/products/lingo-and-optimization-modeling

Parra, E. (1999). Optimización del transporte. Modelos resueltos con SOT II. Includes CD ROM. Madrid: Ed. Díaz de Santos.

Pfeiffer, T., Schiller, U., \& Wagner, J. (2011). Cost-based transfer pricing. Review of Accounting Studies, 16(2), 219-246. https://doi.org/10.1007/s11142-011-9140-0

Tippett, M., \& Wright, B. (2006). The teaching of transfer pricing: Theory and examples. Journal of Accounting Education, 24(4), 173-196. https://doi.org/10.1016/j.jaccedu.2006.05.002

Journal of Industrial Engineering and Management, 2018 (www.jiem.org)

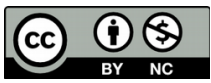

Article's contents are provided on an Attribution-Non Commercial 4.0 Creative commons International License. Readers are allowed to copy, distribute and communicate article's contents, provided the author's and Journal of Industrial Engineering and Management's names are included. It must not be used for commercial purposes. To see the complete license contents, please visit https://creativecommons.org/licenses/by-nc/4.0/. 